\title{
Men's health in Canada: A national survey of urologists
}

Nahid Punjani, $\mathrm{MD}^{1}$; Andrew Di Pierdomenico, $\mathrm{MD}^{2}$, Larry Goldenberg, $\mathrm{MD}^{3}$; Gerald Brock, $\mathrm{MD}^{2}$; Ryan Flannigan, $\mathrm{MD}^{3}$

${ }^{1}$ Weill Cornell Medicine, New York, NY, United States; ${ }^{2}$ Western University, London, ON, Canada;

${ }^{3}$ University of British Columbia, Vancouver, BC, Canada

Cite as: Can Urol Assoc J 2020 July 17; Epub ahead of print.

http://dx.doi.org/10.5489/cuaj.5896

Published online July 17, 2020

$* * *$

\section{Introduction}

Men's health is evolving to incorporate the physical, mental, emotional and social needs of men in addition to their sexual and genitourinary health. ${ }^{1}$ The "Canadian Men's Health Foundation" and the "American Society of Men's Health" acknowledge that men's health is a multidisciplinary field and they advocate for the role of public health and lifestyle change in delaying and preventing the onset of diseases common in men. ${ }^{2,3}$. A need exists for urologists to recognize systemic issues that may lead to worsening illness in their patients and encourage a multifaceted approach to address these. ${ }^{4,5}$

The practice patterns of urologists are variable and may depend upon their subspecialty training and whether a dedicated men's health clinic is affiliated with their center. ${ }^{6}$ Information about the practice patterns of Canadian urologists is limited. We sought to question the practice patterns of Canadian urologists as it relates to men's health and also to query members regarding their preferences pertaining to education around this topic.

\section{Methods}

\section{Recruitment}

On April $23^{\text {rd }}, 2018$, members of the CUA were invited via email to participate in an online survey entitled "Men's Health in Canada." Participants were given eleven days to complete the survey. The survey was closed on May $4^{\text {th }}, 2018$.

\section{Survey and analysis}

The survey was a novel design drafted by experienced urologists and trainees. It comprised three sections: demographics, current scope of practice pertaining to men's health, and interest in education regarding men's health (Figure 1). For survey items with binary responses, the number of affirmative responses were summed and expressed as a percentage of the sample. Questions that were formulated as likert-type items provided 
possible responses ranging from "1. Strongly disagree/Least preferred" to "5. Strongly agree/Most preferred". Each likert-type item was analyzed individually. The range of responses (1-5) for each question were treated as ordinal-level data and the measure of central tendency is expressed as the median response and the interquartile range(IQR).

\section{Results}

A total of 133 survey responses $(15.3 \%)$ were obtained from 868 CUA Members. Of these, $79(9.1 \%)$ surveys were completed by urologists.

\section{Demographics}

Demographic data is summarized in Table 1. The most represented age decile was 50-59 years $(n=20 ; 25 \%)$. The majority of urologists were male $(n=75 ; 95 \%)$, currently in practice $(n=77 ; 97 \%)$, and in a community-based practice $(n=53 ; 54 \%)$. Ontario was the most represented province $(n=33 ; 42 \%)$. Most urologists worked in communities of $<1$ million people $(n=49 ; 62 \%)$ and within a predominantly outpatient setting $(n=45 ; 57 \%)$.

\section{Areas of men's health}

The presentations seen most universally by urologists were BPH/LUTS ( $n=74 ; 95 \%)$, ED $(n=73 ; 92 \%)$ and prostate cancer $(n=71 ; 90 \%)$ (Figure 2$)$. The presentations that the fewest urologists reported seeing were addiction $(n=5 ; 6 \%)$, mental health issues $(n=7$; $9 \%$ ), and $\mathrm{CV}$ disease $(\mathrm{n}=8 ; 10 \%)$. Comparatively, a larger number of urologists endorsed having some exposure to patients with addiction $(\mathrm{n}=17 ; 21 \%)$, mental health issues $(n=32 ; 40 \%)$ and CV disease $(n=18 ; 23 \%)$. The areas of men's health that the most urologists would like to learn more about were metabolic syndrome $(n=25 ; 32 \%)$, testosterone therapy $(n=24 ; 30 \%)$, and strategies towards living a healthy lifestyle $(n=22$; $28 \%)$. The areas of men's health the fewest urologists expressed interest in were trauma $(n=12 ; 15 \%)$, prostate cancer $(n=12 ; 15 \%)$, testicular cancer $(n=11 ; 14 \%)$, and other cancers $(\mathrm{n}=8 ; 10 \%)$.

\section{Insights into CPD and men's health education}

Urologists most commonly earned CPD credits from attendance at association meetings $(n=75 ; 95.0 \%)$, hospital rounds $(n=65 ; 82.3 \%)$ and review of journal articles $(n=68$; $86.1 \%$ ) (Table 2). Urologists agreed that their understanding of men's health was informed by previous lecture attendance (median 4, IQR 4-5), conference attendance (median 4, IQR 4-5), and clinical practice guidelines (median 4, IQR 4-5). The most common motivations for wanting to learn more about men's health were a professional interest $(n=59 ; 75 \%)$ and the perceived benefit to their patients $(n=57 ; 72 \%)$.

When queried about educational activities, urologists expressed interest in a men's health supplemental review article series (median 4, IQR 4-4), as well as the integration of a men's health curriculum into an existing association meeting (median 4, 
IQR 4-4). Regarding the method to communicate such a curriculum, urologists indicated they would prefer a lecture-based format (median 4, IQR 4-4).

\section{Discussion}

Few urologists reported seeing men with addiction, mental health issues, CV disease, obesity and metabolic syndrome. These results were anticipated given the role of urologists as consultants in our healthcare system, with the aforementioned conditions generally under the purview of family practitioners. However, a comparatively larger number of urologists endorsed some exposure to these issues, underscoring their presence in patients presenting with urological complaints. Previous associations have been established between urological diseases and men's health issues, for example, between LUTS and metabolic syndrome, hypogonadism and obesity, and cancer with tobacco use. ${ }^{8-11}$ It is likely that urologists are cognizant of these relationships given that the most common topics they would like to learn more about include metabolic syndrome, testosterone therapy, strategies towards living a healthy lifestyle and obesity. We believe this suggests an opportunity to meet the educational desires of our members with a curriculum pertaining to men's health. Members expressed an interest in this curriculum taking the form of a review article series or a dedicated session incorporated into an existing association meeting. Correspondingly, these are the formats urologists have previously used to inform themselves about men's health and where many have obtained CPD credits previously.

The interpretation of our results is limited by misclassification bias which more detailed survey instructions may have mitigated. The small sample size limited the statistical interrogation of our results and restricts the generalizability of our findings. Important queries pertaining to more detailed demographic variables (ie. fellowship training) were not made. Questions probing the management decisions (ie. referrals made, testing ordered, prescribing decisions) of urologists may have yielded valuable insights. The use of likert-type items did not add appreciably to our insight and may have complicated the interpretation of the data. Despite these shortcomings, this survey represents an initial step in understanding the practice patterns of our members, their educational desires and preferences pertaining to education regarding men's health. 


\section{References}

1. Moon, D. G. Changing men's health: Leading the future. World J Mens Health 2018;36:1-3.

2. Flannigan, R. K., Oliffe, J. L., McCreary, D. R. et al. Composite health behaviour classifier as the basis for targeted interventions and global comparisons in men's health. Can Urol Assoc J 2018;

3. Punjani, N., Flannigan, R., Oliffe, J. L. et al. Unhealthy behaviors among canadian men are predictors of comorbidities: Implications for clinical practice. Am J Mens Health 2018;12:2183-93.

4. Park, H. J. The role of the urologist in men's health. World J Mens Health 2017;35:57-8.

5. Choy, J., Kashanian, J. A., Sharma, V. et al. The men's health center: Disparities in gender specific health services among the top 50 "best hospitals" in america. Asian J Urol 2015;2:170-4.

6. Hawken, S. R., Herrel, L. A., Ellimoottil, C. et al. Trends in inpatient urological surgery practice patterns. Urol Pract 2016;3:499-504.

7. Gorbachinsky, I., Akpinar, H. \& Assimos, D. G. Metabolic syndrome and urologic diseases. Rev Urol 2010;12:e157-80.

8. Shoskes, D. A., Vij, S. C., Shoskes, A. et al. Development of a clinically relevant men's health phenotype and correlation of systemic and urologic conditions. Urology 2018;114:77-82.

9. Engin, A. The definition and prevalence of obesity and metabolic syndrome. Adv Exp Med Biol 2017;960:1-17.

10. Kim, S. W. Men's health: What should we know? World J Mens Health 2015;33:45-9.

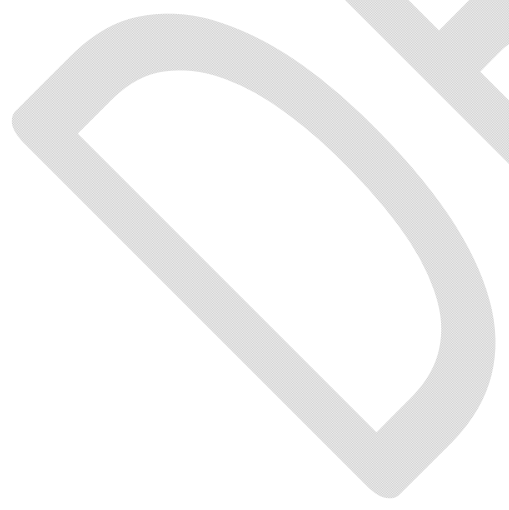




\section{Figures and Tables}

Fig. 1. Men's health survey.

\section{Part 1: Demographics}

1. What is your age?
a) $<30 \quad$ h) $30-39$
c) $40-49$
d) 50-59
e) $60-69$
f) $>70$

2. What gender do you identify with?
a) Male b) Female
c) Other

3. What is your ethnicity?
a) Caucasian
b) African American
c) Asian
d) Hispanic/Latino
e) Aboriginal f) Other

4. What is your location?

5. What best describes the community you live in?
a) Urban $>1$ million
b) Urban $<1$ million_e) Rural

6. What year did you complete your medical training (M.D. or equivalent?)

7. Where did you complete your most post-graduate training (residency or fellowship)?
a) Canada
b) United States
c) Other

8. Are you currently practicing medicine?

a) Yes b) No

9. Which best describes your type of practice?

a) Academic b) Community

10. Where do you spend the majority of your clinical time?
a) Inpatient
b) Outpatient
c) Equal split

\section{Part 2: Men's Health}

1. Which areas of Men's Health:

\begin{tabular}{l|l|l|l} 
& Do you currently see? & $\begin{array}{l}\text { Do you feel } \\
\text { comfortable treating? }\end{array}$ & $\begin{array}{l}\text { Do you want to learn } \\
\text { more about? }\end{array}$ \\
\hline $\begin{array}{l}\text { Erectile Dysfunction } \\
\text { (Treatment and CV }\end{array}$ & & & \\
Disease) & & & \\
\hline $\begin{array}{l}\text { Sexual Dysfunction } \\
\text { (Peyronie's. Disease } \\
\text { and Ejaculatory }\end{array}$ & & & \\
Dysfunction) & & & \\
\hline $\begin{array}{l}\text { Testosterone Therapy } \\
\text { Replacement, CV }\end{array}$ & & & \\
$\begin{array}{l}\text { Disease, Prostate Ca, } \\
\text { Fertility) }\end{array}$ & & & \\
\hline Andropause & & & \\
\hline Fertility/Infertility & & & \\
\hline $\begin{array}{l}\text { Male Pelvic Issues } \\
\text { (pelvic pain and }\end{array}$ & & & \\
prostatitis) & & & \\
\hline BPH/Voiding & & & \\
Dysfunction & & & \\
\hline Prostate Cancer & & & \\
\hline Testicular Cancer & & & \\
\hline Other Cancer \\
(colorectal, lung and \\
bladder)
\end{tabular}




\begin{tabular}{l|l|l|l}
\hline Obesity & & & \\
\hline Metabolic Syndrome & & & \\
\hline $\begin{array}{l}\text { Health Lifestyle } \\
\text { (alcohol, smoking, } \\
\text { diet, exercise and } \\
\text { sleep) }\end{array}$ & & & \\
\hline $\begin{array}{l}\text { Mental Health } \\
\text { (depression and } \\
\text { anxiety) }\end{array}$ & & & \\
\hline Addiction & & & \\
\hline Trauma & & & \\
\hline Other & & & \\
\hline
\end{tabular}

\section{Part 3: Men's Health Education/CPD}

1) In the past I have earned Continuing Professional Development Maintenance of Certification credits from participation in the following activities?

a) Association meetings

b) Invited lecture series/dinner talks

c) Topic specific workshops (i.e. weekend courses, hands-on courses)

d) Hospital rounds (i.e. interesting case rounds, journal clubs, tumor boards)

e) Hospital committees/quality care initiatives

f) Journal articles/practice updates

g) Web-based learning modules

h) Audiotapes/podcasts/webcasts

i) Point-of-care resources (i.e. Un-to-date, Dxpamed)

2) Rate your response to the statement: In the past, the following sources of information (see below) have contributed to my knowledge of Men's Health? (Scale 1-5)

1 - Strongly disagree.

2 - Disagree.

3 - Neutral.

4 - Agree.

5 - Strongly agree.

a) My residency/fellowship training

b) Association meetings/conferences

c) Lectures from experts in the field

d) Published articles

e) Clinical practice guidelines

f) Consultant recommendations

g) Discussion with my peers

h) Discussion with an informed patient

i) Mainstream print media (i.e. newspaper/magazines articles)

j) Mainstream published books

k) The internet

l) Online podcasts or video (i.e. youtube)

m) Documentary film 
3) What are your motivations for wanting to learn more about Men's Health?

a) A professional interest in the material

b) Inadequate education/exposure during my residency/fellowship training

c) It would be beneficial to my patients/practice

d) My patients are expressing interest in it

e) I do not know where to find quality information regarding Men's Health

4) Rate your response to the statement: I would be interested in participating in the following educational activities (see below) to learn about Men's Health? (Scale 1-5)

1- Strongly disagree

2- Disagree

3 - Neutral

4 - Agree

5 - Strongly agree

a) A Men's Health curriculum integrated into my current association meeting(s)

b) A novel national Canadian Men's Health meeting requiring travel

c) An invited Men's Health lecture series/dinner talk(s) in my city

d) A Canadian Men's Health weekend workshop in my city

e) A series of published review papers addressing Men's Health topics from the Canadian perspective

f) A curricula of web-based learning modules addressing Men's Health topics

g) An audiocast/podcast/webcast library of Canadian experts discussing Men's Health issues

h) A Canadian Men's Health website with professional education materials geared towards physicians

5) What would be your preferred format for delivery of educational content at a Men's Health CPD event? (Scale 1-5)

$1-$ Least preferred

$2-$ Not preferred

3 -Neutral

$4-$ Preferred

5 - Most preferred

a) Didactic lectures from experts in the field

b) Interactive workshops

c) Case scenarios with an expert panel

d) Audience Q\&A with an expert panel

e) A PRO/CON debate between experts in the field of a controversial topic

f) Live patient testimonials/success stories

g) Presentations by allied health professionals

h) Presentations by industry

6) True/False. I would participate in educational activities covering Men's Health even if Maintenance of Certification credits were not awarded?

a) True

b) False 
Fig. 2. Urologists and men's health practice. BPH: benign prostatic hyperplasia; $\mathrm{CP} / \mathrm{CPPS}$ : chronic prostatitis/chronic pelvic pain syndrome; CV: cardiovascular; ED: erectile dysfunction; LUTS: lower urinary tract symptoms.

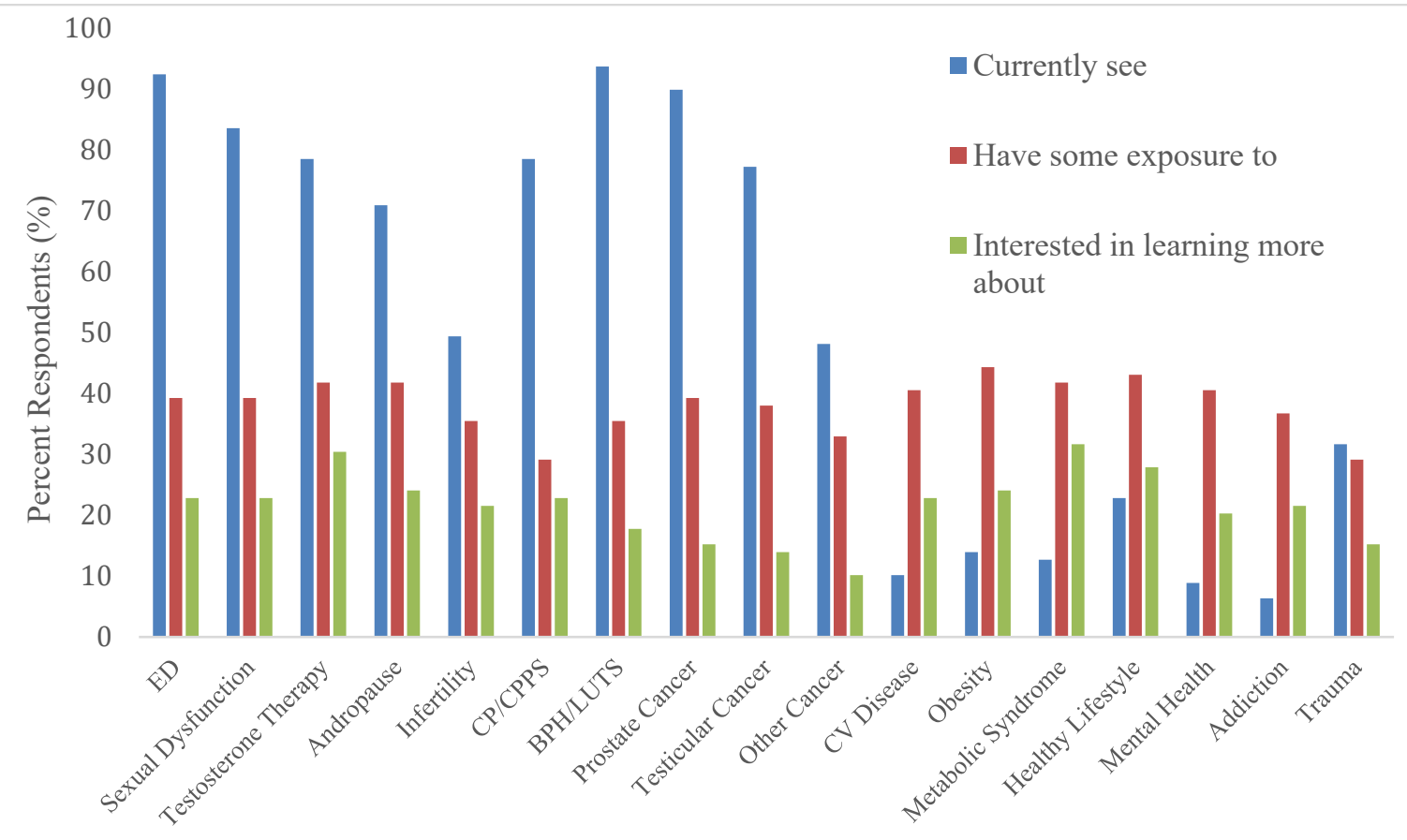

\begin{tabular}{|c|c|}
\hline \multicolumn{2}{|l|}{ Table 1. Respondent demographics $(\mathbf{n}=\mathbf{7 9})$} \\
\hline Characteristic & n (\%) \\
\hline Age decile & $19(24 \%)$ \\
\hline$<40$ & $14(18 \%)$ \\
\hline $40-49$ & $20(25 \%)$ \\
\hline $50-59$ & $18(23 \%)$ \\
\hline $60-69$ & $8(10 \%)$ \\
\hline$>70$ & \\
\hline Gender & $75(95 \%)$ \\
\hline Male & $4(5 \%)$ \\
\hline Female & \\
\hline Currently in practice & $77(97 \%)$ \\
\hline Yes & $2(2 \%)$ \\
\hline No & \\
\hline
\end{tabular}




\begin{tabular}{|c|c|}
\hline Location of practice & $33(42 \%)$ \\
\hline Ontario & $14(18 \%)$ \\
\hline British Columbia & $8(10 \%)$ \\
\hline Quebec & $8(10 \%)$ \\
\hline Alberta & $7(9 \%)$ \\
\hline Other & $11(14 \%)$ \\
\hline Type of community & $38(48 \%)$ \\
\hline Rural & $30(38 \%)$ \\
\hline Urban $<1$ million & $43(54 \%)$ \\
\hline Urban $>1$ million & $35(44 \%)$ \\
\hline Type of practice & $1(1 \%)$ \\
\hline Community & $6(8 \%)$ \\
\hline Academic & $45(57.0 \%)$ \\
\hline Not specified & $27(34.1 \%)$ \\
\hline Practice setting & $1(1.3 \%)$ \\
\hline Inpatient predominant & \\
\hline Outpatient predominant & \\
\hline Equal predominance & \\
\hline Not specified & \\
\hline
\end{tabular}

\begin{tabular}{|l|c|}
\hline Table 2. Men's health education/CPD \\
\hline $\begin{array}{l}\text { I have earned CPD credits from participation in the } \\
\text { following: }\end{array}$ & $\begin{array}{c}\text { Number of respondents } \\
\text { (\%) }\end{array}$ \\
\hline Association meetings & $75(95 \%)$ \\
\hline Journal articles & $68(86 \%)$ \\
\hline Hospital rounds & $65(82 \%)$ \\
\hline Invited lectures & $59(75 \%)$ \\
\hline Workshops & $45(57 \%)$ \\
\hline Web-based modules & $38(48 \%)$ \\
\hline Hospital committees & $33(42 \%)$ \\
\hline Podcasts & $20(25 \%)$ \\
\hline Point of care resources & $19(24 \%)$ \\
\hline $\begin{array}{l}\text { Motivations for wanting to learn more about men's } \\
\text { health: }\end{array}$ & \\
\hline Professional interest & $59(75 \%)$ \\
\hline Beneficial to patients/practice & $57(72 \%)$ \\
\hline Patients are interested & $28(35 \%)$ \\
\hline
\end{tabular}




\begin{tabular}{|c|c|}
\hline Inadequate training/education & $23(29 \%)$ \\
\hline Don't know where to find quality data & $8(10 \%)$ \\
\hline $\begin{array}{l}\text { The following sources of information hav } \\
\text { contributed to my knowledge of men's he }\end{array}$ & Median (IQR) \\
\hline Meetings/conferences & $4(4-5)$ \\
\hline Attendance at lectures & $4(4-5)$ \\
\hline Clinical practice guidelines & $4(4-5)$ \\
\hline Published articles & $4(4-4)$ \\
\hline Residency/fellowship training & $4(3-5)$ \\
\hline Peer discussion & $4(3-4)$ \\
\hline Consultant recommendations & $3(3-4)$ \\
\hline The internet & $3(3-4)$ \\
\hline Podcasts/videos & $3(2-4)$ \\
\hline Discussion with an informed patient & $3(2-3)$ \\
\hline Mainstream media & $3(2-3)$ \\
\hline Mainstream books & $3(2-3)$ \\
\hline Documentary film & $3(2-3)$ \\
\hline \multicolumn{2}{|c|}{$\begin{array}{l}\text { I would be interested in participating in the } \\
\text { following educational activities about men's health: }\end{array}$} \\
\hline Integrated men's health curriculum & $4(4-4)$ \\
\hline Published series & $4(4-4)$ \\
\hline Novel Canadian men's health meeting & $4(3-4)$ \\
\hline Lecture series & $4(3-4)$ \\
\hline Web-based modules & $4(3-4)$ \\
\hline Men's health website & $4(3-4)$ \\
\hline Webcast & $3(2-4)$ \\
\hline \multicolumn{2}{|c|}{$\begin{array}{l}\text { Preferred content for delivery of content at a men's } \\
\text { health educational event: }\end{array}$} \\
\hline Lecture based & $4(4-4)$ \\
\hline Interactive workshops & $4(3-4)$ \\
\hline Cases with a panel & $4(3-4)$ \\
\hline Audience Q\&A with an expert panel & $4(3-4)$ \\
\hline Debate & $4(3-4)$ \\
\hline Presentations by allied health professionals & $3(2-3)$ \\
\hline Patient testimonials & $2(1-3)$ \\
\hline Presentations by industry & $2(1-3)$ \\
\hline
\end{tabular}

IQR: interquartile range. 